\title{
SALTING-OUT PARAMETERS OF GAS SOLUBILITY IN AQUEOUS SALT SOLUTIONS*
}

KAKUSABURO ONDA, EIZO SADA, TAKESHI KOBAYASHI, SHIGEHARU KITO AND KUNIMITSU ITO

Department of Chemical Engineering, Nagova Uuiversity, Nagoya, Japan

\begin{abstract}
Solubilities of carbon dioxide and ethylene in water and a number of aqueous salt solutions are measured at about $\mathrm{I}$ atm. and $25^{\circ} \mathrm{C}$ by the gas volumetric method. A experimental results are correlated by the modified empirical Setschenow equation. The salting-out parameters which ccnsist of three components ascribed to gas, cation and anion in aqueous salt solution, are estimated from the results of this experiment as well as from those listed in International Critical Tables and Landolt-Börnstein Tables. With these calculated salting-out parameters, the solubilities of gas in aqueous salt solutions are predicted accurately within the standard deviation 0.052 . Nine more species of gas, sixe more species of cation and five more species of anion than the data by van Krevelen and Hoftijzer include are taken into account.
\end{abstract}

\section{Introduction}

The investigation of solubilities of gases in liquids has been described in many intensive thermodynamical discussions. On the other hand, many basic equilibrium data for gas-liquid systems are required to design industrial equipment, such as gas absorption columns and chemical reactors for gas-liquid heterogeneous systems. However, the data must be obtained from experimental results, since there is no adequate method of estimation for the solubility of gas in liquid except for systems which may be regarded as a regular solution.

The solubilities of gases in aqueous salt solutions have been measured for a number of systems. At the same time, although many theories have been developed, such as the hydration theory by Rothmund ${ }^{16)}$, the electrostatic theory by Debye and McAulay ${ }^{27}$, van der Waals theory by Kortüm ${ }^{9}$ and the internal pressure concept given by $\operatorname{Tamman}^{18}$, no theoretical relation gives accurate solubilities for gas-aqueous salt solution systems.

As for the activity coefficients of nonelectrolyte solute in aqueous salt solution, Long and $\mathrm{McDevit}{ }^{11)}$ developed the following equation.

$$
\log \left(f_{i} / f_{w}\right)=\log \left(\alpha_{w} / \alpha_{i}\right)=k_{s} C_{s}
$$

The above equation is of the same form as the wellknown Setschenow relation ${ }^{17}$. The empirical Setschenow equation usually holds well but another empirical parameter $k$ should be used in this case instead of $k_{s}$, which is the theoretically significant salt parameter.

Markham and $\mathrm{Kobe}^{12}$ ) have proposed the following equation, which contains two parameters.

$$
-\stackrel{S}{S_{w}}=a_{1} m+\frac{1}{1+a_{2} m}
$$

However, the parameters have to be determined by experiments in both equations.

van Krevelen and Hoftijzer ${ }^{19)}$ have modified the

\footnotetext{
* Received on May 15, 1969
}

Setschenow equation. They have regarded the parameter $k$ as the sum of constants which are characteristic of gases, cations and anions as follows

$$
k=x_{g}+x_{c}+x_{a}
$$

Moreover,' they have assumed that $x_{c}$ and $x_{a}$ are independent of temperature and only $x_{\theta}$ is dependent on it, and have proposed that ionic strengh $I$ should be used instead of $C_{s}$. As a result, Eq. (1) is represented as follows

where

$$
\log \left(\alpha_{w} / \alpha\right)=k I
$$

$$
I=\frac{z_{c}^{2} C_{e}+z_{a}^{2} C_{a}}{2}
$$

In their paper, the method used to determine the values of $x_{q}, x_{c}$ and $x_{a}$ is not described and the ionic strength is restricted to the range of less than $2 \mathrm{~mol} / l$. In industry, gas absorption towers are usually operated with solutions of ionic strength more than $2 \mathrm{~mol} / l$.

In this paper, solubilities of carbon dioxide and ethylene in a number of aqueous salt solutions, of which ionic strength is more than $2 \mathrm{~mol} / l$, are measured at about $1 \mathrm{~atm}$. and $25^{\circ} \mathrm{C}$, and it is also shown how to determine the values of $x_{g}, x_{c}$ and $x_{a}$. These values are estimated from the results of the experiments as well as from those listed in International Critical Tables ${ }^{8)}$ and Landolt-Börnstein Tables ${ }^{10)}$.

\section{Experimental}

\section{1-1. Apparatus and procedure}

The apparatus used in this investigation is shown in Fig. 1. The principle of this method is that a measured volume of gas is brought into contact with a measured quantity of gas-free liquid, equilibrium is established by agitation using a magnetic stirrer and the volume of remaining gas is measured. The change in volume gives the amount dissolved by the liquid. Experimental pro. cedures are as follows: 


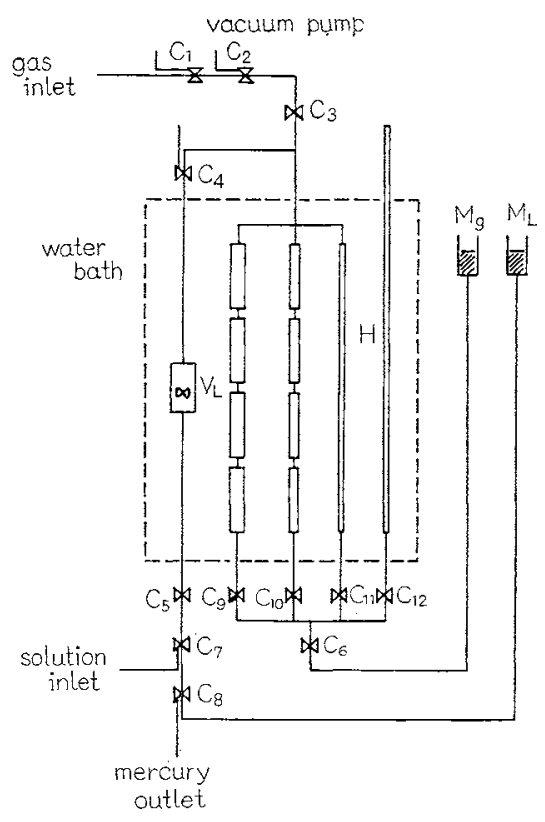

Fig. I Schematic diagram of experimental apparatus

(1) The aquecus salt solution in the flask is degassed by boiling under reduced pressure, cooled to ordinary temperature, and connected with the solution inlet $C_{7}$ without being exposed to the atmosphere.

(2) The level of mercury in the gas chamber is set at the standard lines on the lower part, and stopcocks $C_{9} \sim$ $C_{12}$ are closed.

(3) Closing the stopcock $C_{i}$, the system is evacuated through stopeocks $C_{2} \sim C_{5}$

(4) With stopcock $C_{4}$ closed and $C_{7}$ open, the degassed solution is introduced into $V_{L}$ up to about $90 \%$ of its volume.

(5) Stopcock $C_{7}$ is opened to mercury bulb $M_{L}$ and mercury is introduced into $V_{L}$

(6) Solute gas is introduced into the gas chamber through stopcocks $C_{1}$ and $C_{2}$

(7) When the whole of the system attains a constant temperature, stopcock $C_{3}$ is closed and stopcocks $C_{4}$ and $C_{8}$ are opened. The mercury in $V_{L}$ will start falling, and when its level coincides with the standard line, stopcocks $C_{4}$ and $C_{8}$ are closed. The mercury collected in the beaker is measured.

(8) The magnetic stirrer is set to rotate. To maintain equilibrium, the levels of mercury in. $M_{g}, H$ and gas chambers are adjusted to the same level.

Gas and liquid chambers are calibrated by filling with mercury. A cathetometer is used for the gas chamber reading. The experimental apparatus is immersed in a water bath, the temperature of which is controlled within the range $\pm 0.01^{\circ} \mathrm{C}$.

The solutions are made by weighing the proper amount of analytical grade salt and dissolving in a weighed amount of freshly boiled distilled water. The concentration of each solution is verified by measuring the density, and comparing with values from the literature, or analyzed by evaporating a known weight of salt solution and weighing the dry salt as done by Markham and $\mathrm{Kobe}^{12)}$.

The gases are taken from commercial cylinders. The purity of the carbon dioxide is $99.8 \%$ and that of the ethylene is $99.6 \%$.

\begin{tabular}{|c|c|c|c|c|c|}
\hline \multicolumn{5}{|c|}{$\begin{array}{l}\text { Table } 1 \text { Observed results for carbon dioxide } \\
\text { in aqueous salt solution at } 1 \text { atm. and } 25^{\circ} \mathrm{C}\end{array}$} & \multirow[b]{2}{*}{$\alpha$} \\
\hline system & $C_{s}[\mathrm{~mol} / \mathrm{ll}]$ & $\alpha$ & system $C$ & $C_{s}[\mathrm{~mol} / l]$ & \\
\hline \multirow[t]{5}{*}{$\mathrm{LiCl}$} & 1.004 & 0.6288 & $\mathrm{Na}_{2} \mathrm{SO}_{4}$ & 0.540 & 0.5242 \\
\hline & 1.256 & 0.5977 & & 0.678 & 0.4742 \\
\hline & 1.940 & 0.5305 & & 1.436 & 0.2867 \\
\hline & 3.613 & 0.3950 & $\mathrm{HNO}_{3}$ & 1.482 & 0.7910 \\
\hline & 5.053 & 0.3182 & $\mathrm{CaCl}_{2}$ & 0.178 & 0.7003 \\
\hline \multirow[t]{8}{*}{$\mathrm{NaCl}$} & 0.500 & 0.6644 & & 0.287 & 0.6646 \\
\hline & 0.603 & 0.6489 & & 0.403 & 0.6279 \\
\hline & 0.999 & 0.5972 & & 0.551 & 0.5920 \\
\hline & 1.000 & 0.5941 & & 0.812 & 0.5267 \\
\hline & 1.153 & 0.5686 & & 1.220 & 0.4471 \\
\hline & 2.000 & 0.4712 & & 1.404 & 0.4120 \\
\hline & 3.001 & 0.3776 & & 2.169 & 0.2986 \\
\hline & 3.005 & 0.3729 & $\mathrm{Ca}\left(\mathrm{NO}_{3}\right)_{2}$ & 20.304 & 0.6847 \\
\hline \multirow{6}{*}{$\mathrm{NH}_{4} \mathrm{NO}_{3}$} & 1.177 & 0.7214 & & 0.701 & 0.5993 \\
\hline & 2.015 & 0.6974 & & 1.340 & 0.4810 \\
\hline & 2.615 & 0.6906 & & 1.619 & 0.4356 \\
\hline & 2.644 & 0.6917 & & 2.110 & 0.3647 \\
\hline & 3.372 & 0.6640 & $\mathrm{NaHSO}_{3}$ & 0.505 & 0.6528 \\
\hline & 3.632 & 0.6616 & & 1.017 & 0.5524 \\
\hline \multirow[t]{5}{*}{$\mathrm{BaCl}_{2}$} & 0.371 & 0.6325 & & 2.015 & 0.3917 \\
\hline & 0.539 & 0.5852 & KI & 1.003 & 0.6640 \\
\hline & 0.835 & 0.4961 & & 2.002 & 0.5976 \\
\hline & 1.082 & 0.4482 & & & \\
\hline & $\begin{array}{l}\text { Table } 2 \\
\text { aqueous salt }\end{array}$ & $\begin{array}{l}\text { Observed } \\
\text { solution a }\end{array}$ & $\begin{array}{l}\text { esults for et } \\
\mathrm{latm} \text {. and }\end{array}$ & $\begin{array}{l}\text { thylene in } \\
25^{\circ} \mathrm{C}\end{array}$ & \\
\hline system & $C_{s}[\mathrm{~mol} / / \mathrm{l}]$ & $\alpha$ & system $C$ & $C_{s}[\mathrm{~mol} / l]$ & $\alpha$ \\
\hline \multirow[t]{7}{*}{$\mathrm{NaCl}$} & 0.524 & 0.0925 & $\mathrm{NH}_{4} \mathrm{NO}_{3}$ & 0.537 & 0.1050 \\
\hline & 1.123 & 0.0759 & & 1.973 & 0.0879 \\
\hline & 1.538 & 0.0674 & & 2.426 & 0.0839 \\
\hline & 2.170 & 0.0552 & & 2.793 & 0.0798 \\
\hline & 2.619 & 0.0467 & & 3.793 & 0.0713 \\
\hline & 3.805 & 0.0331 & $\mathrm{Na}_{2} \mathrm{SO}_{4}$ & 0.206 & 0.0916 \\
\hline & 4.224 & 0.0284 & & 0.448 & 0.0734 \\
\hline \multirow[t]{9}{*}{$\mathrm{BaCl}_{2}$} & 0.123 & 0.1038 & & 0.718 & 0.0587 \\
\hline & 0.256 & 0.0951 & & 0.944 & 0.0471 \\
\hline & 0.439 & 0.0847 & & 1.139 & 0.0392 \\
\hline & 0.456 & 0.0834 & $\mathrm{Na}_{2} \mathrm{SO}_{3}$ & 0.141 & 0.1011 \\
\hline & 0.793 & 0.0665 & & 0.267 & 0.0932 \\
\hline & 0.889 & 0.0646 & & 0.455 & 0.0770 \\
\hline & 0.954 & 0.0601 & & 0.747 & 0.0600 \\
\hline & 1.521 & 0.0422 & & 0.818 & 0.0592 \\
\hline & 1.741 & 0.0379 & & & \\
\hline
\end{tabular}

\section{1-2. Experimental results}

Gas solubility is expressed by the Bunsen coefficient. This coefficient expresses the volume of gas dissolved, at $0^{\circ} \mathrm{C}$ and $760 \mathrm{~mm}$. $\mathrm{Hg}$ partial gas pressure. The gas volume is corrected based on the ideal gas law.

The accuracy and reliability of the equipment and procedure are determined by measurements of the solubilities of carbon dioxide and ethylene in pure water. The average values of the Bunsen coefficients determined at $25^{\circ} \mathrm{C}$ for six runs are 0.7595 with a range of $\pm 0.17 \%$ for carbon dioxide and 0.1111 with a range of $\pm 1.44 \%$ for ethylene. These values agree quite well with the values reported in International Critical Tables.

The results obtained in this experiment are given in Tables 1 and 2. Figs. 2 and 3 show the logarithm of the ratio of solubilities in water and in aqueous salt solution as a function of ionic strength for carbon dioxide and Fig. 4 shows those for ethylene. For already observed systems, the results are also presented in these figures, and results obtained in this experiment agree well with 


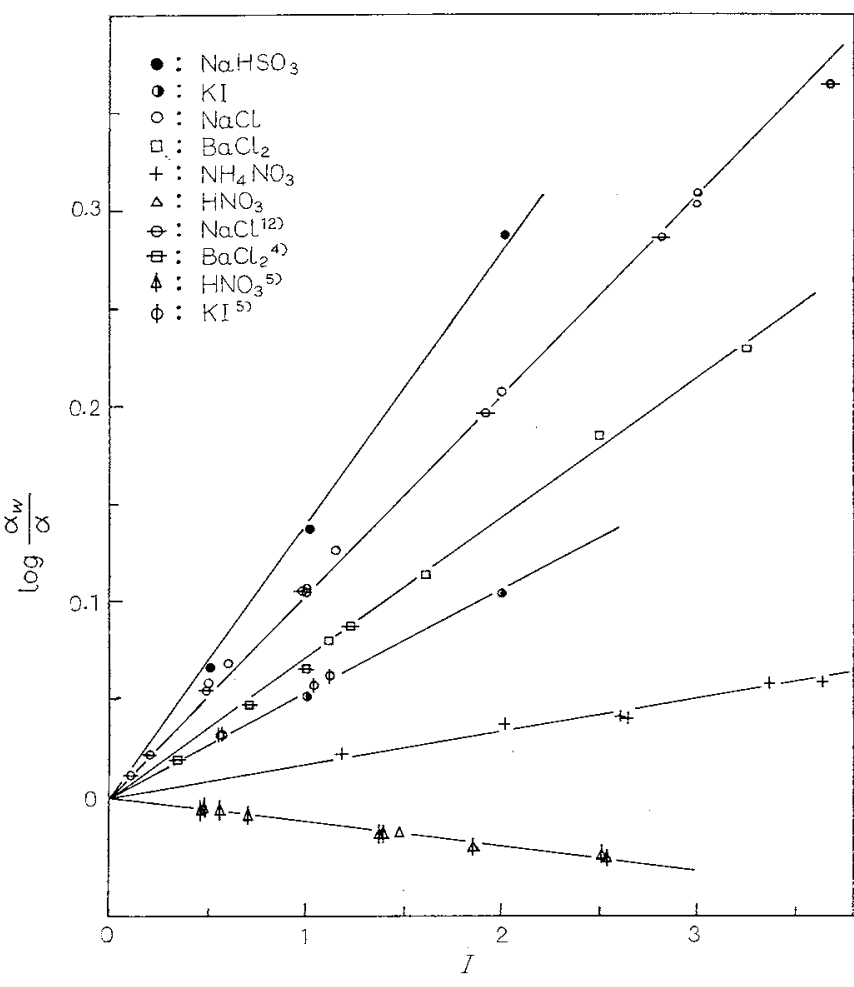

Fig. 2 Experimental results for carbon dioxide at $1 \mathrm{~atm}$. and $25^{\circ} \mathrm{C}$

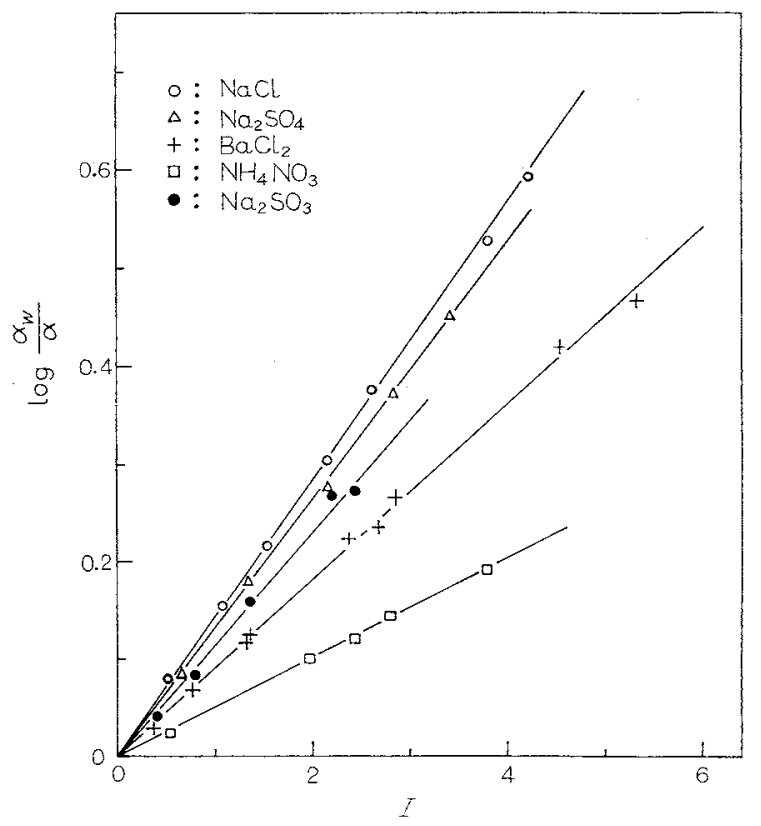

Fig. 4 Experimental results for ethylene at $1 \mathrm{~atm}$. and $25^{\circ} \mathrm{C}$

the results of other investigators. Straight lines in these figures are calculated from Eq. (8).

\section{Correlation by a Modified Setschenow Equation}

The experimental results as well as those listed in International Critical Tables and Landolt-Börnstein Tables

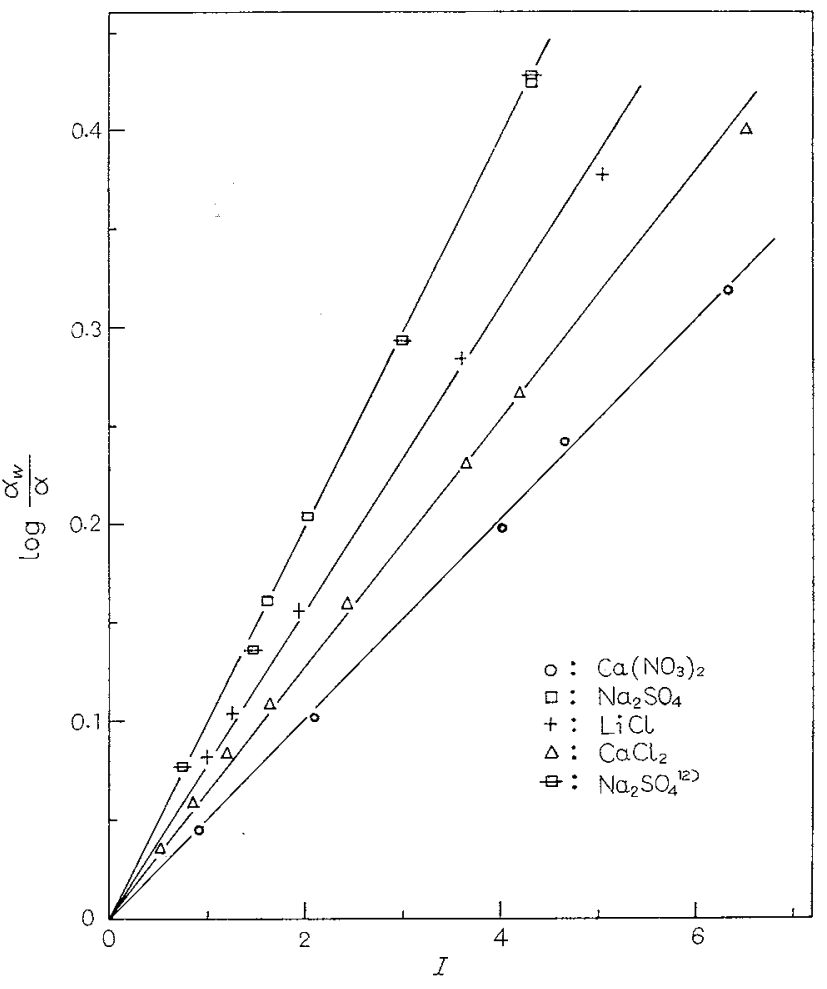

Fig. 3 Experimental results for carbon dioxide at I atm. and $25^{\circ} \mathrm{C}$

are correlated by a modified empirical Setschenow equation.

Eq. (4) can be written as follows:

$$
\frac{\alpha_{w}}{\alpha}=10^{\left(x_{0}+x_{c}+x_{a}\right) I}
$$

or

$$
x_{g}+x_{c}+x_{a}=\log \left(\alpha_{w} / \alpha\right) / I
$$

When observed $\alpha w / \alpha$ vs. $I$ are plotted on a semi-logalithmic graph, as shown in Fig. 2, they scatter a little from the straight line. The average values of the right side of Eq. (7), $b_{g, c, a}$, are determined as follows by the least square method.

$$
b_{g, c, a}=\frac{\sum_{j=1}^{m}\left(I_{j} \log \frac{\alpha_{w}}{\alpha_{j}}\right)}{\sum_{j=1}^{m} I_{j}{ }^{2}}
$$

When $v$ is taken as follows,

$$
v=b_{g, c, a}-\left(x_{g}+x_{c}+x_{a}\right)
$$

$x_{g}, x_{c}$ and $x_{a}$ can be determined for the minimum values of $\sum v^{2}$. Thus $\partial \sum v^{2} / \partial x_{g i}=0$ for gas $i$, the following equation is obtained.

$$
\sum b_{g i,,}=n_{g i} x_{g i}+\sum x_{\varepsilon}+\sum x_{a}
$$

where $\sum b_{g i_{1}}$, is the sum of all $b_{g, c, a}$ for observed gas $i ; n_{g i}$ is the number of the observed systems for gas $i$; and $\sum x_{c}$ and $\sum x_{a}$ are the sums of the constants of cation and anion, respectively, for the system containing gas $i$. In the same way, for cation and anion, the following equations are obtained.

$$
\begin{aligned}
& \sum b_{, c i}=\sum x_{g}+n_{c i} x_{c i}+\sum x_{a} \\
& \sum b_{, a i}=\sum x_{g}+\sum x_{e}+n_{a i} x_{a i}
\end{aligned}
$$

where $n_{c i}$ and $n_{a i}$ are the numbers of the observed 
systems of the cation and anion, respectively. Since the sum of the number of species of observed gases and ions is equal to the number of simultaneous equations obtained from Eqs. (10), (11) and (12), the most appropriate values of $x_{g}, x_{e}$ and $x_{a}$ are determined. These values are obtained by the Gauss-Seidel method, using a digital computer.

The calculated results of $x_{g}, x_{c}$ and $x_{a}$ are shown in Table 3 as well as their standard deviations, calculated from the following equation.

$$
\sigma=\sqrt{\frac{1}{n} \sum\left(\frac{\alpha_{\mathrm{cal}}-\alpha_{\mathrm{obs}}}{a_{\mathrm{obs}}}\right)^{2}}
$$

Using these values, Bunsen coefficients calculated from Eq. (4) are compared with the observed results in this experiment, in Fig. 5.

Nine more species of gas, six more species of cation and five more species of anion than are included in the data by van Krevelen and Hoftijzer are taken into account.

In Figs. 6 and 7, $x_{g}$ values in Table 3 are plotted against the temperature. In these figures, $x_{g}$ values for each gas in aqueous $\mathrm{NaCl}$ solution at various temperatures are also plotted to show the applicability of $x_{q}$ values in Table 3 (i. e., these plotted values are calculated from the observed $k$ values in one system by applying Eq. (3) and $x_{c}$ and $x_{a}$ values in Table 3 ).

Effect of pressure on the value of $x_{g}$ is shown in Fig. 8. Only a few solubility data at high pressure are reported. Values of $x_{g}$ calculated from the solubility of methane in sodium chloride aqueous solution are plotted in Fig. 8. As is clear from this figure, the effect of pressure on $x_{g}$ value seems to be small. Thus the solubility of gas in aqueous salt solution may be estimated from Eqs. (3), (4) and (5), assuming that $x_{g}$ value does not depend on pressure up to ca. 200atm.

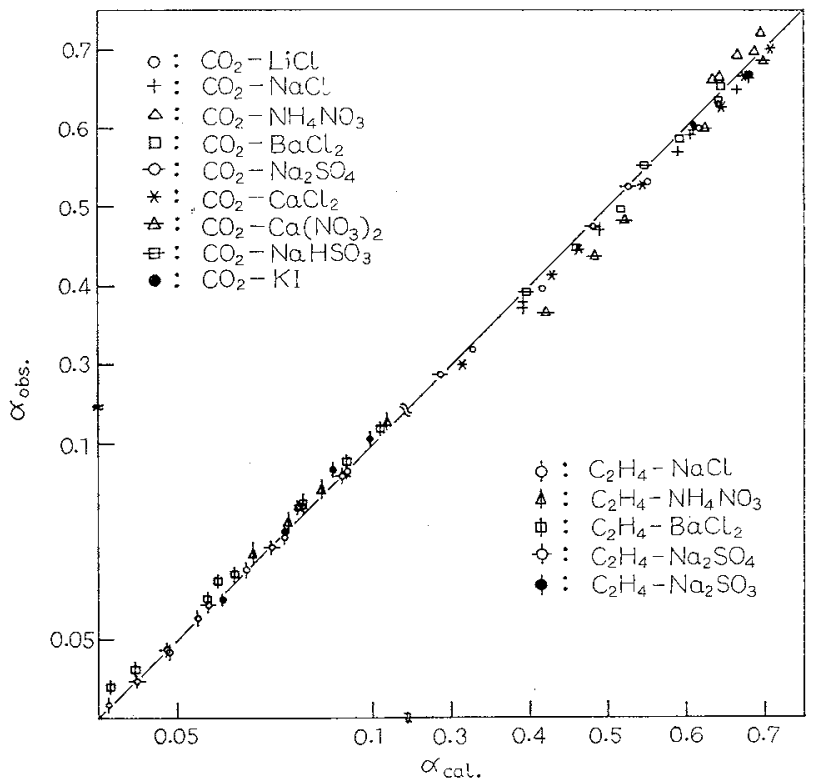

Fig. 5 Comparison of observed and calculated Bunsen absorption coefficients

\section{Table 3 Calculated results}

Temperature is shown in parentheses

\begin{tabular}{|c|c|c|c|c|}
\hline & overall & $\begin{array}{c}\sigma \\
0.0522\end{array}$ & $\begin{array}{c}\sigma^{\prime} \\
0.0508\end{array}$ & $\begin{array}{c}\sigma^{\prime \prime} \\
0.0689\end{array}$ \\
\hline gas & $x_{y}$ & $\sigma$ & $\sigma^{\prime}$ & $\sigma^{\prime \prime}$ \\
\hline $\mathrm{CO}_{2}$ & -0.2277 & 0.0560 & 0.0587 & 0.0811 \\
\hline $\mathrm{N}_{2}$ & -0.1904 & 0.0779 & - & - \\
\hline $\mathrm{O}_{2} \quad$ (25) & -0.1892 & 0.0542 & 0.0542 & 0.0486 \\
\hline $\mathrm{H}_{2} \quad$ (25) & -0.2115 & 0.0678 & 0.0578 & 0.0703 \\
\hline $\mathrm{N}_{2} \mathrm{O}$ & -0.2141 & 0.0433 & 0.0318 & 0.0355 \\
\hline $\mathrm{C}_{2} \mathrm{H}_{2}$ (25) & -0.2240 & 0.0518 & 0.0556 & 0.0833 \\
\hline $\mathrm{H}_{2} \mathrm{~S}$ (25) & -0.2551 & 0.0744 & 0.0744 & 0.0767 \\
\hline $\mathrm{SO}_{2} \quad(25)$ & -0.3154 & 0.0406 & 0.0435 & 0.0509 \\
\hline $\mathrm{NH}_{3}(25)$ & -0.2394 & 0.0528 & 0.0528 & 0.1554 \\
\hline $\mathrm{C}_{2} \mathrm{H}_{4}(25)$ & -0.1951 & 0.0666 & - & - \\
\hline $\mathrm{He}$ (25) & -0.2220 & 0.0226 & 一 & - \\
\hline $\mathrm{Ne} \quad(25)$ & -0.2240 & 0.0178 & - & - \\
\hline Ar (25) & -0.1866 & 0.0164 & 一 & - \\
\hline $\mathrm{Kr}_{\mathrm{r}} \quad$ (25) & -0.1762 & 0.0349 & - & 一 \\
\hline $\mathrm{N}_{2} \mathrm{O}$ & -0.2143 & 0.0410 & 0.0456 & 0.0729 \\
\hline $\mathrm{N}_{2} \mathrm{O}(10)$ & -0.2156 & 0.0523 & 0.0603 & 0.0834 \\
\hline $\mathrm{N}_{2} \mathrm{O}$ (15) & -0.2118 & 0.0412 & 0.0443 & 0.0426 \\
\hline $\mathrm{N}_{2} \mathrm{O}(20)$ & -0.2128 & 0.0279 & 0.0268 & 0.0317 \\
\hline $\mathrm{N}_{2} \mathrm{O}(40)$ & -0.2179 & 0.0256 & 0.0256 & 0.0654 \\
\hline $\mathrm{CO}_{2} \quad(0)$ & -0.2110 & 0.0482 & 0.0482 & 0.0663 \\
\hline $\mathrm{CO}_{2}$ (15) & -0.2222 & 0.0412 & 0.0365 & 0.0348 \\
\hline $\mathrm{CO}_{2}(40)$ & -0.2327 & 0.0695 & 0.0695 & 0.1820 \\
\hline$(0)$ & -0.1653 & 0.1021 & 0.1021 & 0.1043 \\
\hline (15) & -0.1786 & 0.0476 & 0.0476 & 0.0507 \\
\hline $\mathrm{O}_{2} \quad(20)$ & -0.1771 & 0.0832 & 0.0837 & 0.0551 \\
\hline (5) & -0.2106 & 0.0184 & 0.0184 & 0.0221 \\
\hline (10) & -0.2170 & 0.0175 & 0.0175 & 0.0267 \\
\hline $\mathrm{H}_{2} \quad$ (15) & -0.2197 & 0.0920 & 0.0497 & 0.0758 \\
\hline$(20)$ & -0.2132 & 0.0187 & 0.0454 & 0.0439 \\
\hline $\mathrm{C}_{2} \mathrm{H}_{2}(15)$ & -0.2124 & 0.0528 & - & - \\
\hline $\mathrm{SO}_{2}$ & -0.3122 & 0.0415 & 一 & - \\
\hline $\mathrm{C}_{2} \mathrm{H}_{4}(15)$ & -0.2003 & 0.0471 & - & - \\
\hline cation & $x_{c}$ & $\sigma$ & $\sigma^{\prime}$ & $\sigma^{\prime \prime}$ \\
\hline $\mathrm{Li}^{+}$ & -0.0416 & 0.0365 & $\ldots$ & - \\
\hline $\mathrm{Na}^{+}$ & -0.0183 & 0.0471 & 0.0419 & 0.0459 \\
\hline $\mathrm{K}^{+}$ & -0.0362 & 0,0541 & 0.0443 & 0.0517 \\
\hline $\mathrm{Cs}^{+}$ & -0.0584 & 0.0101 & - & - \\
\hline $\mathrm{Mg}^{++}$ & -0.0568 & 0.0721 & 0.0752 & 0.1602 \\
\hline $\mathrm{Ca}^{++}$ & -0.0547 & 0.0731 & 0.0774 & 0.0847 \\
\hline $\mathrm{Ba}^{++}$ & -0.0473 & 0.0322 & 0.0186 & 0.0212 \\
\hline $\mathrm{Al}^{+++}$ & -0.0726 & 0.0820 & - & - \\
\hline $\mathrm{NH}_{4}^{+}$ & -0.0737 & 0.0577 & 0.0555 & 0.0676 \\
\hline $\mathrm{H}^{+}$ & -0.1110 & 0.0570 & 0.0575 & 0.0619 \\
\hline $\mathrm{Rb}^{+}$ & -0.0449 & 0.0149 & - & - \\
\hline $\mathrm{Cd}^{++}$ & -0.0062 & 0.0274 & - & - \\
\hline $\mathrm{Zn}^{++}$ & -0.0590 & 0.0340 & 0.0340 & 0.0662 \\
\hline $\mathrm{Sr}^{++}$ & -0.0445 & 0.0290 & - & - \\
\hline $\mathrm{Fe}^{++}$ & -0.0602 & 0.0260 & 0.0260 & 0.0372 \\
\hline $\mathrm{Co}^{++}$ & -0.0534 & 0.0608 & 0.0608 & 0.0559 \\
\hline $\mathrm{Ni}^{++}$ & -0.0520 & 0.0511 & 0.0511 & 0.0474 \\
\hline $\mathrm{Cr}^{+++}$ & -0.0986 & 0.0929 & - & - \\
\hline $\mathrm{Mn}^{++}$ & -0.0625 & 0.0456 & 0.0456 & 0.0617 \\
\hline anion & $x_{\alpha}$ & $\sigma$ & $\sigma^{\prime}$ & $\sigma^{\prime \prime}$ \\
\hline $\mathrm{Cl}^{-}$ & 0.3416 & 0.0441 & 0.0471 & 0.0515 \\
\hline $\mathrm{Br}^{-}$ & 0.3310 & 0.0403 & 0.0410 & 0.0373 \\
\hline $\mathrm{I}^{-}$ & 0.3124 & 0.0156 & 0.0309 & 0.0221 \\
\hline $\mathrm{SO}_{4}^{--}$ & 0.3446 & 0.0589 & 0.0602 & 0.0930 \\
\hline $\mathrm{NO}_{3}{ }^{-}$ & 0.3230 & 0.0524 & 0.0499 & 0.0754 \\
\hline $\mathrm{CO}_{3}^{--}$ & 0.3754 & 0.1873 & 0.0872 & 0.2156 \\
\hline $\mathrm{OH}^{-}$ & 0.3875 & 0.0453 & 0.0521 & 0.0585 \\
\hline $\mathrm{CNS}^{-}$ & 0.2612 & 0.0494 & - & 一 \\
\hline $\mathrm{PO}_{4}^{---}$ & 0.3265 & 0.1209 & 一 & - \\
\hline $\mathrm{SO}_{3}^{--}$ & 0.3275 & 0.1142 & - & - \\
\hline $\mathrm{HSO}_{3}{ }^{-}$ & 0.3869 & 0.0126 & - & 一 \\
\hline $\mathrm{HS}^{-}$ & 0.3718 & 0.0103 & - & - \\
\hline
\end{tabular}




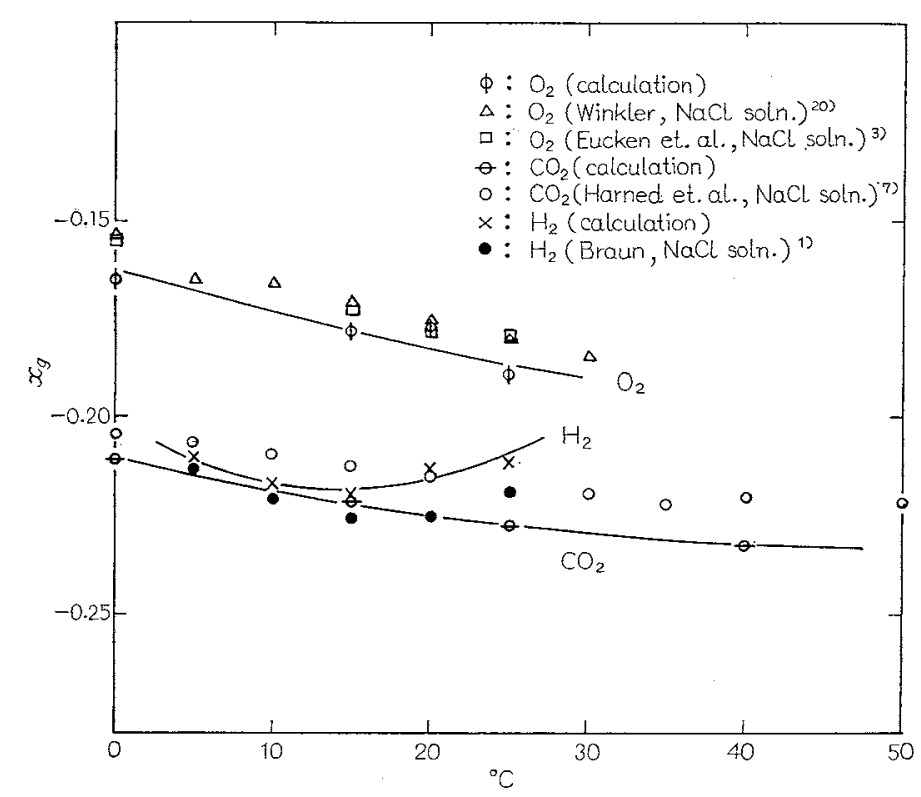

Fig. 6 Effect of temperature on $x_{g}$

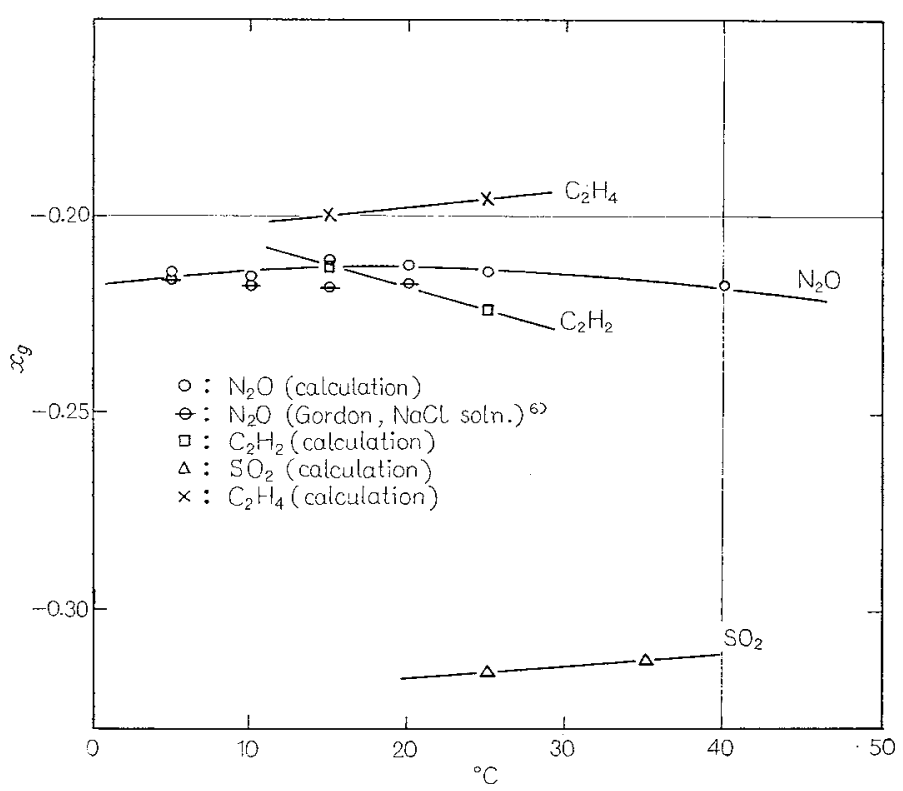

Fig. 7 Effect of temperature on $x_{0}$

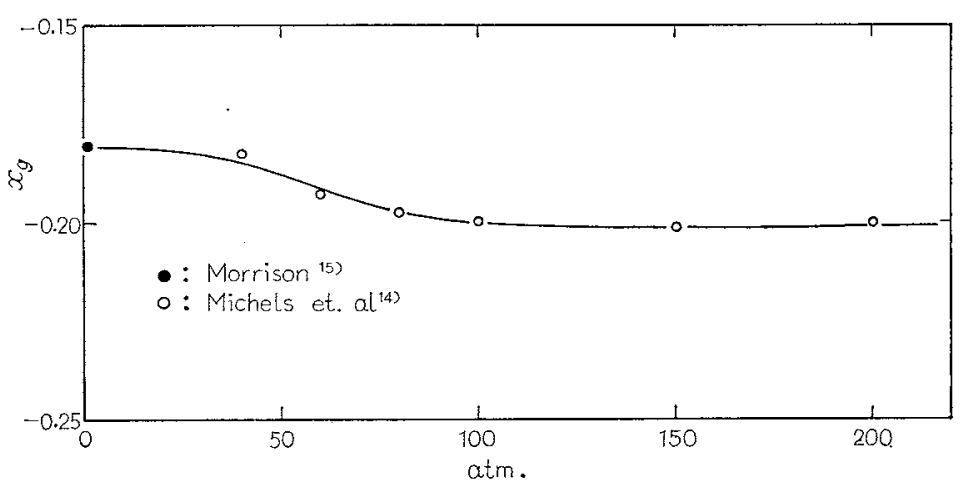

Fig. 8 Effect of pressure on $x_{g}$ of methane in $\mathrm{NaCl}$ solution at $25^{\circ} \mathrm{C}$

\section{Discussion}

There are three main points to be discussed for this study, i. e. the restriction of the Setschenow equation, the assumption made by van Krevelen and Hoftijzer and the unreliability of solubility data.

First, the modified Setschenow equation shows that the relation between $\log \left(\alpha_{w} / \alpha\right)$ and $I$ is linear, and this 
is right at low concentrations of electrolyte solution. Further, it holds well in general even if the concentration of electrolyte solution is high, as is shown in Fig. 2. However, there are a few systems in which it does not hold. For example, in the system of carbon dioxide and aqueous solution of sulfuric acid, the plot of $\alpha$ vs. weight percent of sulfuric acid has two minima, as is shown in Markham and Kobe ${ }^{13)}$. Hence, in these cases, the effectiveness of the Setschenow equation is restricted, and the data which do not obey the modified Setschenow equation are omitted in this paper. (Appendix)

Second, the mechanism of dissolved gases is different for various gas species. For example, non polar gases such as oxygen or hydrogen dissolve in aqueous solution as gas molecules, while polar gases such as carbon dioxide or sulfur dioxide dissolve in different ways. In the case of carbon dioxide, part of the gas molecules dissolved in aqueous solution react with water to produce $\mathrm{H}_{2} \mathrm{CO}_{3}$ and part of it dissociates into $\mathrm{HCO}_{3}{ }^{-}$ion. Moreover, it may be dissociated further. Thus carbon dioxide in aqueous solution exists as not only $\mathrm{CO}_{2}$ molecule but also $\mathrm{H}_{2} \mathrm{CO}_{3}$ molecule, $\mathrm{HCO}_{3}{ }^{-}$ion and $\mathrm{CO}_{3}{ }^{--}$ion. However, it is assumed that these different ways for the dissolution of gases are the same and can be represented by a single parameter $x_{g}$.

Finally, in spite of the same system, there are some unreliable solubility data, such as for the system of carbon dioxide and aqueous solution of sodium chloride. In such cases the data are omitted. However, in the system for which only a few data are reported, these are used for calculation.

In spite of the troubles above mentioned, it is obvious from the standard deviations in Table 3 that comparatively good predictive results are obtained.

To compare with the results of van Krevelen and Hoftijzer, standard deviations are calculated for the same systems mentioned in their paper, and are shown in the fourth and fifth columns of Table 3 . It is clear from this table that, in most cases, the results of this study are more reliable than those obtained by van Krevelen and Hoftijzer. When it is considered that the ranges of concentration of electrolyte solution are enlarged and more systems than that by van Krevelen et al. are taken into account, this smaller deviation than Krevelen's seems to be worthwhile.

\section{Conclusion}

Solubilities of carbon dioxide and ethylene in a number of aqueous salt solutions are measured at $1 \mathrm{~atm}$. and $25^{\circ} \mathrm{C}$. The experimental results as well as those listed in International Critical Tables and Landolt-Börnstein Tables are correlated by a modified empirical Setchenow equation. With these calculated salting-out parameters, solubilities of gas in aqueous salt solutions will be. predicted within the standard deviation 0.052 . Effects of temperature and pressure on $x_{g}$ value are also studied.

Though the range of concentration of electrolyte solution and the number of species are larger, the standard deviations are smaller than that of van Krevelen et al..

\begin{tabular}{ccccccc}
\hline \multicolumn{5}{c}{$\begin{array}{c}\text { Table 4 } \\
\text { for Eq. (4) }\end{array}$} & \multicolumn{3}{c}{ Upper limits of ionic strength available } \\
$\mathrm{CO}_{2}$ & $\mathrm{~N}_{2}$ & $\mathrm{O}_{2}$ & $\mathrm{H}_{2}$ & $\mathrm{~N}_{2} \mathrm{O}$ & $\mathrm{C}_{2} \mathrm{H}_{2}$ & $\mathrm{H}_{2} \mathrm{~S}$ \\
15.1 & 2.5 & 5.6 & 10.0 & 8.6 & 12.2 & 7.1 \\
$\mathrm{SO}_{2}$ & $\mathrm{NH}_{3}$ & $\mathrm{C}_{2} \mathrm{H}_{4}$ & $\mathrm{He}$ & $\mathrm{Ne}$ & $\mathrm{Ar}$ & $\mathrm{Kr}$ \\
6.0 & 2.0 & 5.3 & 1.0 & 1.0 & 2.5 & 1.0 \\
\hline
\end{tabular}

\section{Appendix}

In the system $\mathrm{CO}_{2}-\mathrm{H}_{2} \mathrm{SO}_{4}$ above mentioned, there are observed data up to higher ionic strength, and it is ascertained in this case that Eq. (4) can be used in the range $I<11 \mathrm{~mol} / l$. In the system $\mathrm{CO}_{2}-\mathrm{Cs} \mathrm{Cl}$, however, what range of ionic strength is to be used in Eq. (4) cannot be ascertained because only one datum $(I=0.55 \mathrm{~mol} / l)$ is reported. Thus, in the case where the gas dissolves in a number of aqueous salt solution, the upper limit of the concentration of salt solution adaptable for the Setschenow equation is quite various. Therefore, the determination of the ionic strength of the gas adaptable in Eq. (4) is almost impossible. Thus, for convenience, the maximum ionic strength for each ass species is shown in Table 4.

\section{Nomenclature}

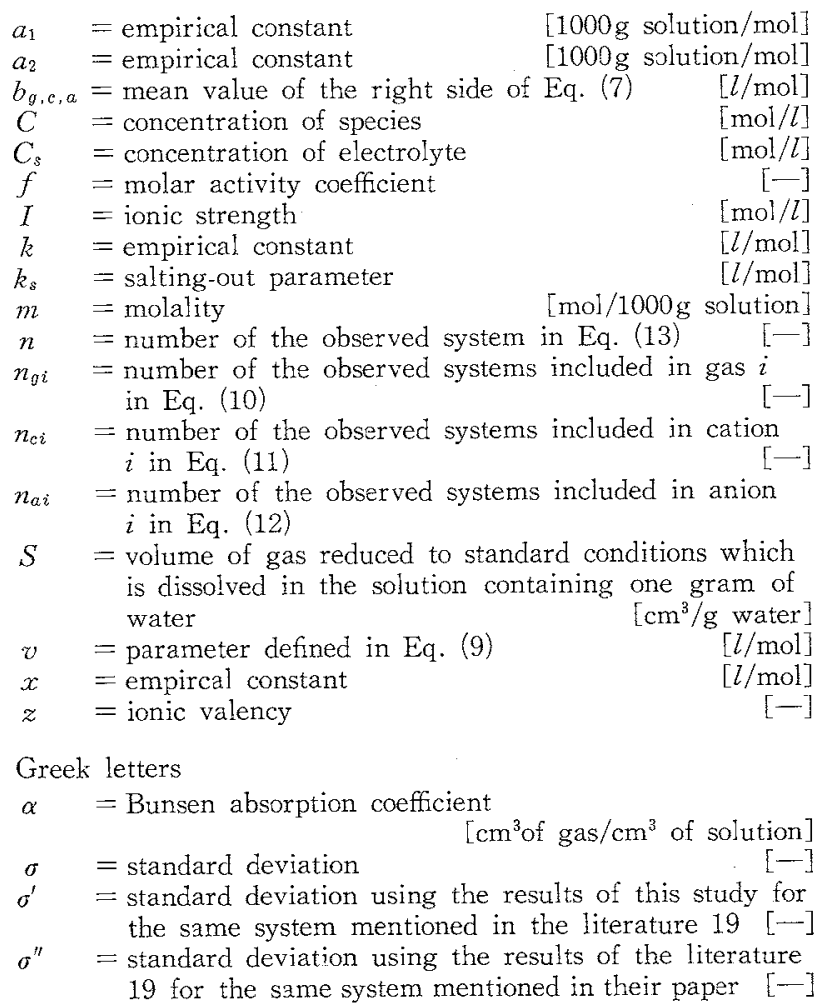

$$
\begin{aligned}
& \text { Subscripts } \\
& \begin{aligned}
a & =\text { anion } \\
c & =\text { cation } \\
g & =\text { gas } \\
i & =i \text { species } \\
w & =\text { water }
\end{aligned}
\end{aligned}
$$

\section{Literature Cited}

1) Braun, L.: Z. Physik. Chem., 33, 721 (1900)

2) Debye, P. and J. McAulay: Physik. Z., 26, 22 (1925)

3) Eucken, A. and G. Z. Hertzberg: Z. Physik. Chem., 195, 1 (1950)

4) Findlay, A. and B. Shen: J. Chem. Soc., 105, 291 (1914) 
5) Geffcken, G.: Z. Physik. Chem., 49, 257 (1904)

6) Gordon, V.: ibid., 18, 1 (1895)

7) Harned, H.S. and R. S. Davis Jr.: J. Am. Chem. Soc., 65 $2030(1943)$

8) International Critical Tables, McGraw-Hill, New York, 3, 271 (1928)

9) Kortü, G.: Z. Electrochem, 42, 287 (1936)

10) Landolt-Börnstein Tables, Springer, Berlin, II. Band 2, Teil, 1-1 (1962)

11) Long, F. A. and W. F. McDevit: Chem. Rev., 51, 119 (1952)

12) Markham, A.E. and K. A. Kobe: J. Am. Chem. Soc., 63,
$449(1941)$

13) Markham, A.E. and K. A. Kobe: ibid, 63, 1165 (1941)

14) Michels, A., J. Gerver and A. Bi1: Physica, 3, 797 (1936)

15) Morrison, T. J. and F. Billett: J. Chem. Soc., 3819 (1952)

16) Rothmund, V. : Löslichkeit und Löslichekeitsbeeinflussung.

Barth, Leipzig (1907)

17) Setschenow, J.: Z. Physik. Chem., 4, 117 (1889)

18) Tamman, G. : ibid, 11, 676 (1893)

19) van Krevelen, D. W. and P. J. Hoftijzer: Chim. Ind.

$\mathrm{XXI}^{\text {eme }}$ Congr. Int. Chim. Ind., 168 (1948)

20) Winkler, L. W.: Ber., 22, 1764 (1889)

\title{
LIQUID BEHAVIOUR IN BUBBLE COLUMN
}

\author{
EIICHI KUNUGITA, ${ }^{* *}$ MICHIO IKURA AND TSUTAO OTAKE \\ Department of Chemical Engineering, Faculty of \\ Engineering Science, Osaka Unitersity, Toyonaka, Osaka
}

\begin{abstract}
The motion of a solid particle which was allowed to drift in a liquid phase was pursued by a camera to find the following :

(1) There is no remarkable irregularity of liquid flow in the bubble column.

(2) The distribution function of axial displacements of a solid particle was discribed by the normal distribution function. The assumed dispersion model coincided well with the experimental results. From this fact the mechanism of the mixing of liquid element was considered to be analogous to that of diffusion. The dispersion coefficient was also determined experimentally.

(3) The dynamic behaviour of bubbles, especially the coalescence of bubbles, has the controlling effect on the gas holdup and the dispersion coefficient.
\end{abstract}

\section{Introduction}

Bubble columns are often used as gas-liquid reactors in many chemical industries. However, their chracteristics are not yet fully made clear. When the bubble column is used as a reactor, many problems such as the heat transfer between liquid and column wall, the mass transfer between liquid and bubbles, and the mixing of liquid and bubbles, become important.

Up to this time, every investigation of liquid mixing in the bubble column analyzed the axial dispersion model using sodium chloride or potassium chloride as a tracer. Siemes and Weiss ${ }^{8)}$ recorded the transient response to a liquid tracer pulse in a column without liquid phase flow. Tadaki and Maeda $^{9}$ analyzed liquid mixing in a column with countercurrent flow by the pulse response to a liquid tracer. Argo and Cova ${ }^{2)}$ carried out an investigation by measurement of the steady state concentration gradient of the tracer for continuous tracer injection with a continuous liquid flow. Bischoff and Phillips ${ }^{3)}$ used the same experimental method as that of Tadaki and Maeda ${ }^{9}$ in a concurrent column. Reith, Renken and Israel $^{7)}$, and Aoyama, Ogushi, Koide and Kubota ${ }^{17}$ measured the steady state concentration gradient of the tracer as in Argo and Cova's method ${ }^{22}$. Aoyama et al. "', moreover, used the heat which was generated by a nicrome wire as a tracer.

\footnotetext{
* Received on Apr. 30, 1969

** Dept. of Chem. Eng., Kobe Univ., Kobe
}

Except for the research of Aoyama et al. ${ }^{1)}$, all investigations were carried out using electrolyte as a tracer. Generally the bubble behaviour which causes liquid mixing in the column depends upon the conditions of the gas-liquid interface. For example, Koide, Kato, Tanaka and Kubota ${ }^{6)}$, and Braulick, Fair and Lerner ${ }^{4}$ recognized that the bubble size tends to become smaller by the addition of small amounts of electrolyte to the liquid phase as a tracer. In the present research, a solid particle was pursued by the camera. According to the particle motion observed, the degree of liquid mixing was analyzed using a statistical method.

\section{Experimental}

The experimental apparatus used is shown in Fig. 1 The column (Diameter; $50 \mathrm{~mm}$, Height $; 1000 \mathrm{~mm}$ ), made of clear acrylic plastics, was equipped with a porous plate as a gas distributor. This porous plate had the same diameter as that of the column and the pore size was $60 \mu$. To prevent distortion, the bubble column was surrounded by a clear acrylic plastic box of square section and the space between the box and the column was filled with water which was circulated from the thermostat.

Six mirrors were placed around the bubble column and adjusted to take two mutually perpendicular views of column simultaneously.

The flow patten could be detected by the motion of a solid particle. These optical systems are shown in 